\title{
Fortalecimiento de la identidad afro en Colombia a partir de la salsa choke y su cubrimiento en los medios de comunicación
}

Nicolás Romero

DAVID BARRETO

SANTIAgO BRICEÑO ${ }^{\mathrm{I}}$

\section{Introducción}

A partir de la aprobación en la Constitución Política colombiana de 1991, del artículo $7^{\circ}$, "El Estado reconoce y protege la diversidad étnica y cultural de la Nación colombiana", los afrocolombianos empiezan a ser incluidos en la cultura y en las agendas mediáticas del país ya que los estereotipos de esclavitud son transformados por nuevas percepciones frente a ésta población, haciendo referencia a diversas características propias como la 'belleza negra'.

Del mismo modo, este grupo poblacional comienza a ser reconocido por sus habilidades a nivel deportivo, político y artístico, esto sin duda contribuye al fortalecimiento de la identidad afro a nivel nacional.

Si bien, a partir del surgimiento y auge de la salsa choke en los últimos años, especialmente durante el 2014 cuando los jugadores de la selección colombiana de fútbol celebraban sus goles danzando este baile durante el mundial disputado en Brasil, los estereotipos sobre la

1 Estudiantes de la Facultad de Comunicación Social de la Universidad Santo Tomás. 
comunidad negra nuevamente se hicieron presentes en algunos sectores de la sociedad, tanto así que es frecuente escuchar comentarios racistas en los que se indican por ejemplo que los negros solo sirven para bailar.

Por supuesto, los medios de comunicación colombianos no son ajenos a esta situación y a partir de publicaciones televisivas, radiales, escritas y demás, han logrado que este género musical entre en la agenda mediática del país.

Este género musical recientemente ha tomado una fuerza arrasadora en todos los rincones del país, pero ¿de dónde viene la salsa choke? En un artículo publicado por la Revista Arcadia en el 2015, Carlos José Castro, más conocido como CJ Castro, hombre a quien se le otorga el título del creador de la salsa choke, narra cómo mezcló diversos ritmos para crear la salsa choke en Tumaco. Posteriormente, este reconocido artista expuso cómo fue el arribo y la consolidación de este ritmo en la ciudad de Cali. Para Castro la salsa choke podría convertirse en uno de los géneros más representativos del país, ya que a diferencia de la salsa tradicional, este ritmo fue creado en Colombia "me atrevería a decir que la salsa choke es más nuestra que la misma salsa. Nació aquí, porque de la salsa como tal nosotros ya sabemos sus orígenes" (en Ariza, 2015). Este género musical se ha convertido en un estilo y en un refugio para las personas afros, en el que pueden exaltar a través de la letra de sus canciones sus experiencias, costumbres y problemáticas.

La costa pacífica colombiana se ha encargado de ver el surgimiento de grandes artistas, quienes combinan ritmos alegres y sentimientos. Algo que hay que resaltar es la mezcla y la unión que la salsa choke tiene con el Hip hop, sabiendo que esta música se caracteriza por tener composiciones que reflejan problemáticas y conflictos sociales ligadas con la violencia que vive el país.

Por otro lado, la salsa choke ha revolucionado y ha impactado en ciudades como Quibdó, Buenaventura y Tumaco, así como en sectores del departamento del Chocó. Interpretando esta música a partir de diferentes problemáticas, así, como en el artículo periodístico realizado por El Tiempo, titulado Salsa Choke para dummies, destaca que "Es la nueva expresión musical y corporal del pacifico" (El Tiempo, 2014), consideramos que este ritmo es origen de un fruto de la migración y 
forma de expresión de los sectores afro populares que habitan en sectores populares y que buscan exaltar a nivel nacional e internacional las costumbres, tradiciones y creencias que marcan su identidad.

Sin embargo, sus composiciones y ritmos tienen un estilo que transmite cierto erotismo y sensualidad, es por eso que nos basamos en Mara Viveros Vigoya en que "los encuentros sexuales interraciales no se dan a menudo dentro del respeto y la igualdad de los sexos sino a partir de estereotipos sobre las mujeres negras como objetos de placer y presas fáciles" (2010, p. 25) viendo a la comunidad afro como un sector estigmatizado por el sexismo, por eso se basan en este estilo musical para reflejar las inconformidades y persecuciones que ellos sienten se les están imponiendo socialmente.

Vigoya (2010) también explica que "en muchos de ellos se puede entrever satisfacción frente a unos rasgos que parecen conferirles una cierta superioridad y ser atributos compensatorios de su imagen en el contexto nacional, en el cual ser negro equivale a ser discriminado" (p.5), la comunidad negra ha sido denominada como una raza inferior, haciendo que esta raza sea suprimida por la blanca, generando estereotipos desde un punto de vista negativo, provocando la opresión y la discriminación.

Por otro lado, Colombia es uno de los países de Sur América que genera música de impacto, en este caso, la salsa choke es un género que se ha convertido en una expresión cultural y artística, una propuesta musical que genera un impacto social que lucha por una reivindicación y generación de un cambio, así, como el artículo de la página El Pueblo dice que "El término con el que se identifica este género cultural derivado de la salsa, con sonidos y códigos de baile distintivos, se denomina y se escribe salsa choke, porque somos una propuesta musical cultural y social que genera un impacto, un choque, un cambio" (Charrupi, 2014).

Sin embargo, la salsa choke es una inspiración de sensualidad hacia la mujer, en que su ritmo y composición ve al género femenino como algo digno de respeto y admiración hacia la belleza de la mujer y que por medio de sus letras se haga una respectiva integración e inclusión social. "Lo que se llame género salsa choke nunca vulnerará la dignidad de ningún ser humano. La sensualidad de la mujer es una 
inspiración de este género, pero respetarla es una obligación; los niños son nuestro público más importante, por eso nuestras letras y contenidos procuraran ser digno ejemplo para ellos. Esto es sabrosura responsable e incluyente" (Charrupi, 2014).

Como se mencionó al principio del artículo la salsa choke vivió su auge durante el Mundial de Fútbol de Brasil en el 2014 cuando James Rodríguez, Juan Guillermo Cuadrado y Pablo Armero celebraron sus goles al ritmo del Ras tas tas, produjo que este género estallara mediáticamente de forma masiva, convirtiendo a los cantantes de salsa choke en estrellas de la noche a la mañana, sin que ellos mismo se enteraran. Pero más importante que la fama que algunos de sus exponentes han conseguido, es el logro que obtuvo el género como tal cuando fue proclamado el 21 de mayo del 2014 por el Consejo de la ciudad de Cali, como un género musical único en el mundo y Cali su epicentro.

\section{Imagen 1. Celebración de la Selección Colombia} en mundial de fútbol Brasil 2014

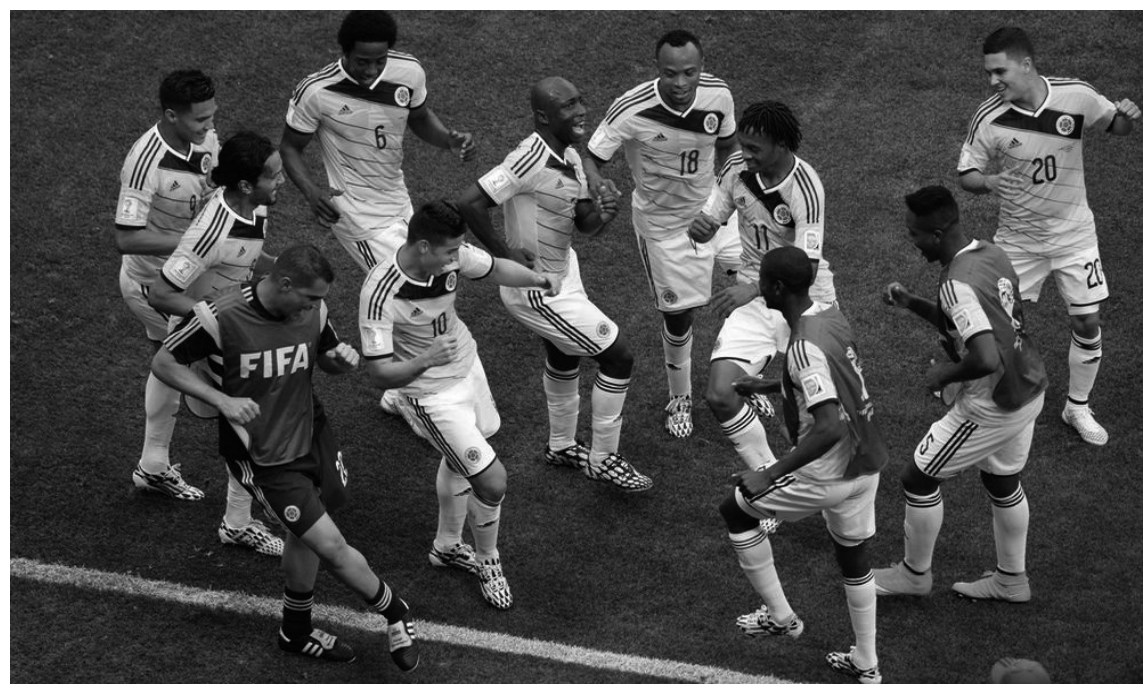

Fuente: Pinterest. (2017). Noticias Principales de Colombia y el Mundo - El Tiempo. [online] Available at: https://es.pinterest.com/pin/474426141969093367/ [Accessed 4 Apr. 2017]. 
Por supuesto no todo es Ras tas tas, de hecho en un artículo escrito por Mariangela Rubbini publicado en el 2014 por la Revista Shock que justamente lleva el título "Salsa chocke es más que Ras Tas Tas", se hace mención a que esta no es la única canción insignia de este género y que de hecho durante el mundial de Brasil, los jugadores de la selección no solo bailaban esta popular melodía sino también la canción llamada "esta rumba va sola". Finalmente Mariangela Rubbini hace énfasis en que los medios de comunicación podrían llegar a sobreexponer este género hasta el punto que sea algo netamente mediático y luego se olvide como ha pasado con tantas otras expresiones artísticas. Según la autora, los medios de comunicación tienen la facilidad de crear y tumbar ídolos de la noche a la mañana, esto también pasa con la música, dentro del bum mediático que tuvo la canción del ras tas tas y la salsa choke, durante y después del Mundial, nos han mostrado una identidad mediática que ha colaborado a que cada día, se escuchen más canciones de salsa choke, pero también ha generado en que adultos y jóvenes bailen al ritmo de este sonsonete, no solo afros sino gente de todo el mundo gracias a la exportación de la música con el fútbol.

Alén (1992) explica que "la fusión de las diferentes culturas africanas con los elementos de las culturas hispánicas dio inicio a un complejo proceso de transculturación al cual, con el tiempo, se le añadieron elementos de otras culturas de posteriores migraciones". A fines del año 2014, la mezcla de fútbol y música siguió compartiendo lugares en la prensa colombiana, en ese momento se empieza configurar este género musical, como "el ritmo oficial de la Selección Colombia" pues así lo titula el periódico El País de Cali, la exportación de este ritmo al mundo se da por medio del fútbol, tanto así "James celebra su primer gol con el Real Madrid al ritmo del Ras Tas Tas" o "James le enseña a bailar a CR7 el Ras tas tas" (Gómez, 2014), esta dialéctica existente entre fútbol y música ha permitido asociar o consolidar nuestra lógica de supremacía racial, en la cual los negros sirven para el deporte, la música y el baile.

Por otro lado, la salsa choke no se ha quedado en una simple expresión musical, pues según la revista "El libre pensador" de la Universidad Externado de Colombia, muchos niños y adolescentes que viven en 
zonas marginales de la ciudad de Cali han utilizado este género para mantenerse alejados de las pandillas, y además han impulsado fundaciones que fomentan el arte y la cultura.

Además, en el país se han creado diversos espacios en donde se le enseña a las personas a bailar este tipo de salsa, que desde que los jugadores de la selección colombiana de fútbol empezaron a bailarla para celebrar sus goles, se ha popularizado en otras ciudades.

Diferentes academias de baile en la ciudad de Cali han empezado a incluir dentro de sus coreografías este tipo de música que exalta la cultura pacífica. Dentro de esas academias y fundaciones, podemos encontrar entre otras a "Delirio", una fundación nacida en el 2006 y que cuenta con más de 500 personas en su personal, que a través de sus presentaciones a nivel nacional e internacional reflejan la cultura pacífica y sus costumbres.

Imagen 2. Bailarinas salsa choke. El País (2014).

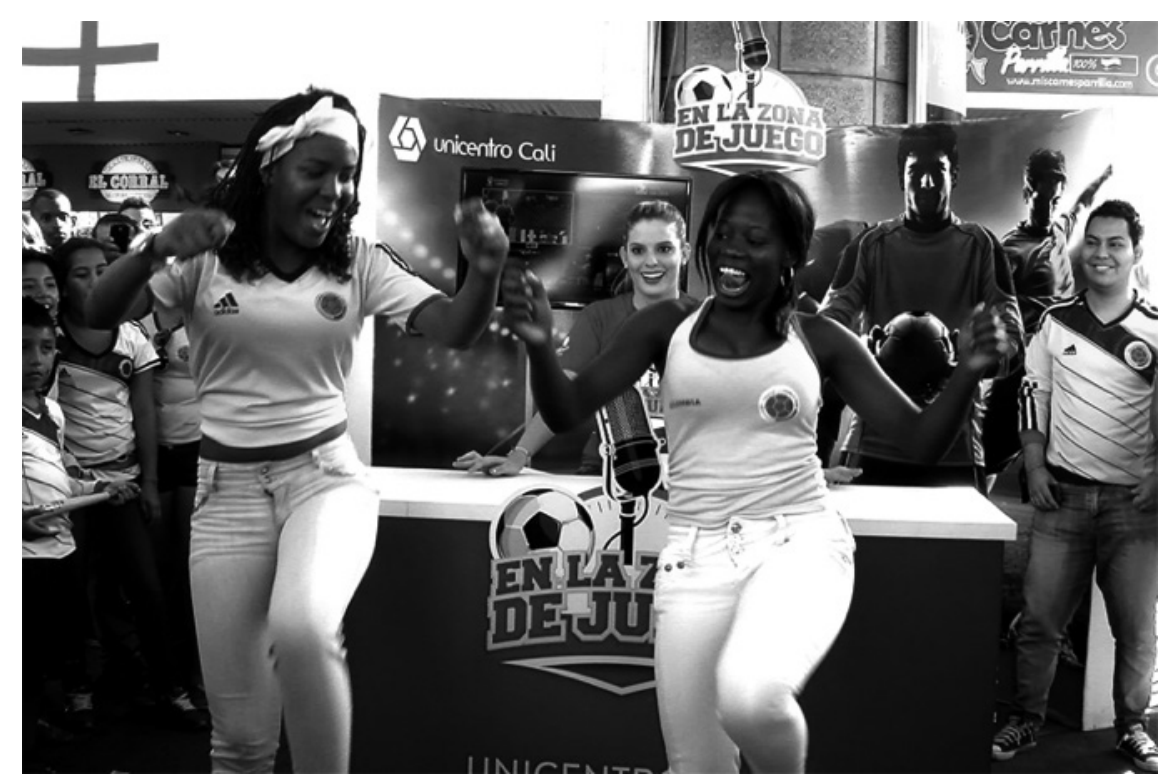




\section{Conclusiones}

La salsa choke sin duda se ha convertido en un género representativo de la cultura afro en Colombia, que por su ritmo y en gran medida por el auge y la promoción que los medios de comunicación le han dado ha atravesado barreras raciales en el país y ha generado que no solo personas negras sino la sociedad en general llegue a disfrutar de este género. No está mal que se exalte la cultura negra, pero lamentablemente la idea original de sus canciones se ha ido perdiendo con los años y ha perdido poco a poco su valor y sentido original.

A partir de la salsa choke la población negra puede resaltar sus costumbres, creencias y experiencias a través de la letra de sus canciones.

Los jugadores de la selección colombiana de fútbol hicieron que este género se popularizara a nivel nacional. Particularmente durante el Mundial de Fútbol de Brasil en 2014.

Gracias a la mezcla con diferentes ritmos como el hip hop, este ritmo surgido en el Pacífico colombiano logró afianzarse como género musical único en el mundo.

\section{Referencias}

Alén, O. (1992) De lo Afrocubano a la Salsa. San Juan: Editorial Cubanacán.

Ariza, P. (2015). ¿Cómo nació la salsa choke? Revista Arcadia. Recuperado de http://www.revistaarcadia.com/impresa/reportaje/articulo/origen-salsa-choke-cali-chichoky/44679Bowers, N. (2015). Salsa Choke, el ritmo afro que mueve a todo un país. El libre pensador. Universidad Externado de Colombia. Recuperado de http://librepensador.uexternado.edu.co/ salsa-choke-el-ritmo-afro-que-mueve-a-todo-un-pais/

Cátedra electiva Estudios Afrocolombianos y Afroamericanos, 2016-1

Charrupi, R. (2014). Salsa choke, el futuro. El Pueblo. Recuperado de http:// elpueblo.com.co/salsa-choke-el-futuro/

El País. (2014). Bailarinas salsa choke. Recuperado de http://www.elpais.com. co/elpais/sites/default/files/multimedia/videos/2014/06/29/salsa-choke-unicentro-cali-brasil-2014.jpg

El Tiempo. (2012). Página de Cultura y Entretenimiento. Catalina Oquendo, 12 de julio del 2014 
Gómez, V. (2014). Abece de la salsa shoke, el 'ritmo oficial' de la Selección Colombia. Revista El País. Recuperado de http://www.elpais.com.co/ elpais/cali/noticias/abece-salsa-shoke-ritmo-oficial-seleccion-colombia

Pinterest. (2017). Noticias Principales de Colombia y el Mundo - El Tiempo. [online] Recuperado de https://es.pinterest.com/pin/474426141969093367/ [Accessed 4 Apr. 2017].

Rubinni, M. (2014). Salsa choke es màs que Ras tas tas. Revista Shock. Recuperado de http://www.shock.co/cultura/articulos/ salsa-shocke-es-mas-que-ras-tas-tas-62252

Vigoya, M. (2010). Dionisios negros Estereotipos sexuales y orden racial en Colombia. Recuperado de http://lasa.international.pitt.edu/LASA98/ViverosVigola.pdf 